\title{
Tuberculosis of Thyroid Gland Presenting as Abscess
}

\section{Veena Gupta, Ekta Boombak, Parul Tanwar*, Hemant Yadav and Rajeev Sen}

Department of Pathology, Post Graduate Institute of Medical Sciences, Rohtak, Haryana, India

\section{Introduction}

Tuberculosis of thyroid gland is an extremely rare clinical entity [1]. It is very rare even in countries with a high prevalence of tuberculosis [2]. It is rare to suspect a thyroid swelling or nodule as being tuberculous on clinical examination, unless it has destroyed the gland and formed an abscess in a patient with known pulmonary tuberculosis [3]. We present a case of thyroid tuberculosis presenting as a solitary nodule and diagnosed on FNAC.

\section{Case Report}

A 20 year old female presented with a swelling in right lobe of thyroid (Figure 1) for 8 days. There was no history of fever, malaise, weight loss or any other generalized symptoms. It was not associated with difficulty in deglutition or change in voice. On examination there was a $3 \times 3 \mathrm{~cm}$ swelling in the right lobe of thyroid which was moving with deglutition. Surface was smooth and overlying skin was normal.

Routine hematological investigations and serum $\mathrm{T}_{3}, \mathrm{~T}_{4}$ and $\mathrm{TSH}$ were within normal range. Chest $\mathrm{X}$ ray did not reveal any abnormality.

Neck ultrasonography showed a $46 \times 42 \times 21 \mathrm{~mm}$ thick walled cystic mass lesion involving right thyroid lobe (Figure 2). This cystic mass showed thick, irregular wall with central fluid and echogenic debris with peripheral vascularity.

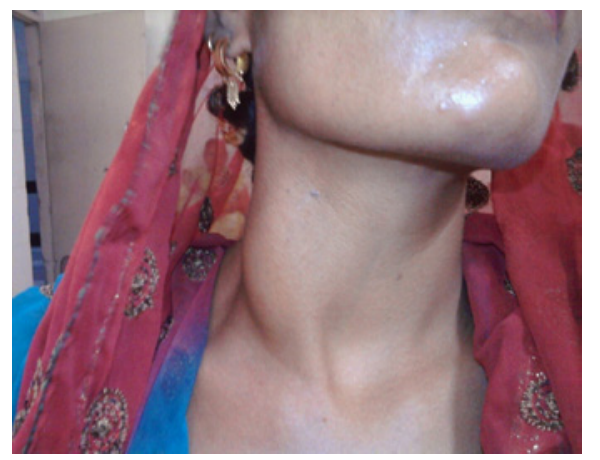

Figure 1: Female presented with a swelling in right lobe of thyroid.

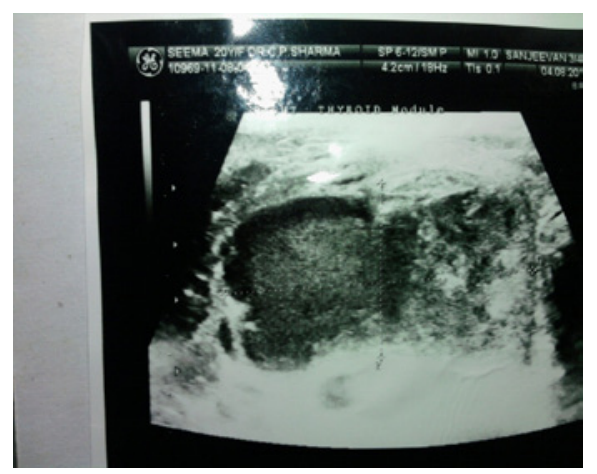

Figure 2: Neck ultrasonography showed a $46 \times 42 \times 21 \mathrm{~mm}$ thick walled cystic mass lesion involving right thyroid lobe.
FNA from right lobe of thyroid was performed which yielded purulent aspirate. Smears examined show degenerated inflammatory cells in a necrotic background (Figure 3). No follicular epithelial cells were seen in the smears. Ziehl Nelson staining with $20 \% \mathrm{H}_{2} \mathrm{SO}_{4}$ was positive (Figure 4). Cytological diagnosis of tubercular inflammation was made. Patient was put on short course antitubercular treatment.

\section{Discussion}

Tuberculosis of the thyroid gland, primary or secondary, is an extremely rare disease. It spread either by lymphogenous route, hematogenous route or by direct extension from adjacent organs.

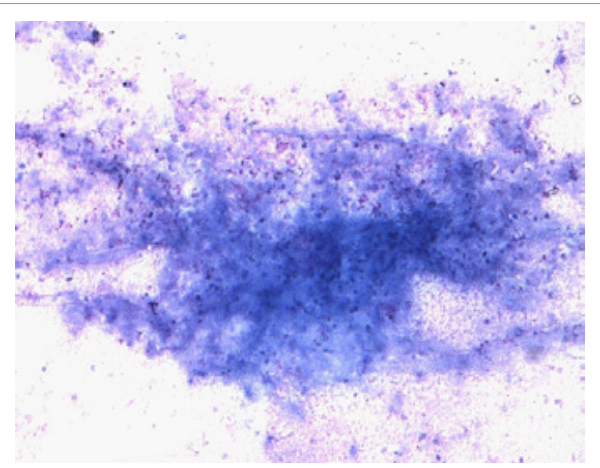

Figure 3: Smears examined show degenerated inflammatory cells in a necrotic background.

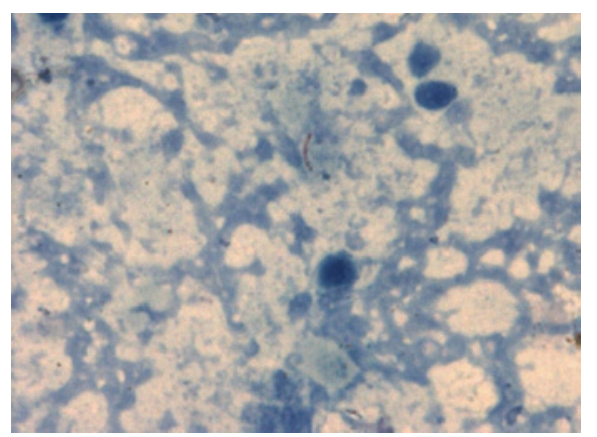

Figure 4: Ziehl Nelson staining with $20 \% \mathrm{H} 2 \mathrm{SO} 4$ was positive.

*Corresponding author: Dr. Parul Tanwar, Department of Pathology, Post Graduate Institute of Medical Sciences, Rohtak, Haryana- 124001, India, Tel: 9868554989; E-mail: drparultanwar@gmail.com

Received July 26, 2012; Accepted September 22, 2012; Published September 24, 2012

Citation: Gupta V, Boombak E, Tanwar P, Yadav H, Sen R (2012) Tuberculosis of Thyroid Gland Presenting as Abscess. J Cytol Histol 3:154. doi:10.4172/21577099.1000154

Copyright: @ 2012 Gupta V, et al. This is an open-access article distributed under the terms of the Creative Commons Attribution License, which permits unrestricted use, distribution, and reproduction in any medium, provided the original author and source are credited. 
Citation: Gupta V, Boombak E, Tanwar P, Yadav H, Sen R (2012) Tuberculosis of Thyroid Gland Presenting as Abscess. J Cytol Histol 3:154. doi:10.4172/2157-7099.1000154

Despite its rarity, thyroid tuberculosis has been the subject of periodic reviews. According to the literature, its frequency is $0.1-0.4 \%$ in histologically diagnosed specimens [4]. In the study by Das et al. [5], the incidence of tuberculous thyroiditis was $0.6 \%$.

Symptoms are non-specific and variable resulting in the differential diagnosis of toxic goiter/hyperthyroidism, acute thyroiditis, riedel thyoiditis and benign nodules. The differentiation from thyroid cancer is essential to avoid unnecessary surgery [6]. Rarity of tuberculosis in thyroid may be due to: colloidal material in the thyroid gland possessing bactericidal action, high blood flow and excess of iodine, enhanced destruction of tubercle bacilli due to increased physiological activity of phagocytes in hyperthyroidism and possible antitubercular roles of thyroid hormone [7].

There are several pathological forms of tuberculous of the thyroid gland described and the most frequent are multiple lesions throughout the gland like miliary tuberculosis, goiter with caseating granulomas, cold abscess formation, sometimes associated with multiple sinuses, chronic fibrosing tuberculosis and acute abscess formation $[8,9]$. Criteria [10] for diagnosis of tuberculosis of thyroid are:

1. Demonstration of AFB in a necrotic or abscessed gland.

2. A definite etiological focus in the body, outside the thyroid. There is no doubt that the presence of AFB on cytological smear is confirmatory evidence of tuberculosis, but sometime it is not possible to demonstrate AFB then the diagnosis of tuberculous thyroiditis can be made only after histopathological examination.

\section{Conclusion}

Thyroid tuberculosis though rare but still exist and should be considered in differential diagnosis of thyroid swelling presenting as abscess. Though most reported cases of thyroid tuberculosis were diagnosed on surgically resected specimens. Fine needle aspiration cytology also contributes in diagnosing thyroid tuberculosis in a thyroid nodule thus, avoiding unnecessary surgery.

\section{References}

1. Pandit AA, Joshi AS, Ogale SB, Sheode JH (1997) Tuberculosis of thyroid gland. Ind J Tub 44: 205-207.

2. Zivaljevic V, Paunovic I, Diklic A (2007) Tuberculosis of the thyroid gland: a case report. Acta Chir Belg 107: 70-72.

3. Hazard JB (1955) Thyroiditis: a review. Am J Clin Pathol 25: 289-298.

4. Coller FA, Huggins CB (1926) Tuberculosis of the Thyroid Gland: A Review of the Literature and Report of Five New Cases. Ann Surg 84: 804-820.

5. Das DK, Pant CS, Chachra KL, Gupta AK (1992) Fine needle aspiration cytology diagnosis of tuberculous thyroiditis. A report of eight cases. Acta Cytol 36: 517-522.

6. Talwar VK, Gupta H, Kumar A (2003) Isolated tuberculosis thyroiditis. JIACM 4: $238-239$.

7. Khan EM, Haque I, Pandey R, Mishra SK, Sharma AK (1993) Tuberculosis of the thyroid gland: a clinicopathological profile of four cases and review of the literature. Aust N Z J Surg 63: 807-810.

8. Tan KK (1993) Tuberculosis of the thyroid gland--a review. Ann Acad Med Singapore 22: 580-582.

9. Bulbuloglu E, Ciralik H, Okur E, Ozdemir G, Ezberci F, et al. (2006) Tuberculosis of the thyroid gland: review of the literature. World J Surg 30: 149-155.

10. Seed L (1939) In Goldberg's Clinical Tuberculosis. (2ndedn), F.A. Davis and Company, Philadelphia. 